\title{
Influence of Superabsorbent Polymers on Moisture Control in Building Interiors
}

\author{
Jan Fořt ${ }^{1,2, * \mathbb{D}}$, Jan Kočí ${ }^{2}$, Jaroslav Pokorný ${ }^{1}$ and Robert Černý ${ }^{2}$ \\ 1 Institute of Technology and Business in České Budějovice, Okružní 517/10, \\ 37001 České Budějovice, Czech Republic; jaroslav.pokorny@mail.vsteb.cz \\ 2 Department of Materials Engineering and Chemistry, Faculty of Civil Engineering, Czech Technical \\ University in Prague, Thákurova 7, 16000 Prague, Czech Republic; jan.koci@fsv.cvut.cz (J.K.); \\ robert.cerny@fsv.cvut.cz (R.Č.) \\ * Correspondence: jan.fort@fsv.cvut.cz
}

Received: 29 March 2020; Accepted: 16 April 2020; Published: 17 April 2020

\begin{abstract}
Moisture loads in building interiors are accompanied by a deterioration of the indoor air quality. Such a phenomenon may induce serious health risks for building inhabitants as well as degradation of furnishing. Unfortunately, the employment of additional heat, ventilation and air conditioning (HVAC) devices does not comply with the sustainability principle due to increased energy consumption, thus cannot be viewed as an efficient solution. This study deals with the use of superabsorbent polymers (SAP) in cement-lime plasters, thus extends the current state of knowledge and outlines further possible development of novel moisture responsive plasters since lightweight aggregates do not provide the desired performance. To be specific, this paper contemplates the experimental analysis of novel plasters modified by $0.5,1$ and $1.5 \mathrm{wt}$. \% of SAP to obtain input parameters for computational modeling. Based on the obtained outputs, the incorporation of SAP admixture resulted in a substantial increase in moisture transport properties including the water absorption coefficient and water vapor diffusion properties. The performed computational modeling revealed a considerable reduction of relative humidity fluctuations, thus mitigation of potential health issues associated with undesired moisture content in building interiors. Achieved results indicate that the SAP enhanced plasters have substantial passive moisture buffering performance and thus may contribute to the improvement of indoor air quality.
\end{abstract}

Keywords: plaster; relative humidity; superabsorbent polymer; moisture moderation; computational modeling

\section{Introduction}

A major share of energy demands is allocated to the maintenance of the indoor thermal comfort, in line with the growing energy consumption of the building sector, the effort aimed at energy savings took place. Specifically, the total energy consumption of the building sector comprises of about $40 \%$ of total energy consumption in Europe. The ambitious energy-saving goals have been set to mitigate the negative effects associated with this issue. Consequently, many types of thermal insulation materials were used to improve the thermal performance of building envelopes and fulfill challenging criteria [1]. Unfortunately, the application of thermal insulation materials resulted in substantial airtightness of buildings [2-4]. Besides the thermal performance of building envelopes, the moderation of the interior level of relative humidity became an important issue in order to achieve and preserve sufficient quality of indoor air [5].

On this account, new challenges associated with the preservation of indoor air conditions, humidity related in particular have been raised. Particularly, the relative humidity problems have 
been distinguished as crucial for securing of human comfort, energy consumption and durability of building materials [6,7]. Considering the durability of building materials, the excessive level of relative humidity may result in accelerated deterioration as stated by [8] who listed several possible damages driven by moisture. Undesired moisture content in masonry structures poses a serious risk associated with the disintegration of inorganic plasters, biological and chemical corrosion, frost damage and salt efflorescence $[9,10]$. Concurrently, the moisture content may induce an adverse effect on the thermal performance of applied insulation materials in building envelopes as a result of a higher thermal conductivity of water compared to dry air [11-13]. Often discussed the issue related to the relative humidity level lays in a substantial problem for building inhabitants. People spend more than $80 \%$ of their time indoors thus securing optimal conditions is crucial to avoid any unfavorable consequences [14]. According to current data, the Sick Building Syndrome (SBS) is connected with a substantial share of modern buildings, public in particular [15]. The syndrome associates several health problems of people who work or live in these areas, such as respiratory illnesses, wheezing, skin or eye irritation and concentration disorders $[16,17]$. Those issues are often related to the level of relative humidity in the rooms, especially during the winter months [18].

As reported by several authors, unfavorable humidity conditions can be mitigated by employing hygroscopic materials used for the moderation of the indoor humidity fluctuations [19]. For this purpose, studies aimed at the utilization of mortars modified by various additives were carried out as a moisture buffering agent [20-22]. Specifically, materials such as bamboo fibers, cellulose, hemp fibers, plywood, lightweight aggregates, porogene additives, and many others were investigated with particular success [21,23-27]. Nonetheless, the obtained benefit was only partial since the moisture buffer value (MBV) was classified as moderate. To provide a more distinct improvement, the attempts aimed at superabsorbent polymers (SAPs) utilization in cement mortars were carried with significant success. Specifically, hygroscopic properties of mortars having $0.9 \mathrm{wt} \%$ of SAP were modified substantially as showed in the work of Senff et al. [28]. Taking into account the desired moisture sorption capacity of SAPs, the application of modern moisture responsive materials can be viewed as beneficial for passive control of the relative humidity level in building interiors due to remarkable improvements in MBV [29]. Nonetheless, current literature lacking data related to the effectivity of composites modified by SAP used for moisture moderation despite the extensive investigation of SAPs for mitigation of autogenous shrinkage in concrete mixtures [30,31]. Only limited information can be obtained from the studies of Senff et al. [32] or Goncalves et al. [33], however, both research teams remained focused only on the material characterization of modified mortars and potential benefits were only presumed.

In light of research gaps in the current literature and substantial demand for passive solutions for the maintenance of interior air quality, this study contemplates the utilization of SAPs in commercial plaster as moisture-responsive agents. First, the hygric parameters of plasters modified by $0.5,1.0$ and $1.5 \mathrm{wt}$. \% of SAP are determined to obtain input parameters for computational modeling employed for the investigation of the effect of SAP-modified plasters on the interior relative humidity.

\section{Experimental}

\subsection{Materials}

The commercial cement-lime plaster composed of cement, lime, sand in 1:1:5 was used as the reference material. Considering the main objective of this study, the plaster was modified by $0.5,1$ and $1.5 \mathrm{wt} \%$ of Creasorb SAP (Evonik, Essen, Germany). The particle size was $25 \mu \mathrm{m}$ accordingly to performed particle size analysis with the help of laser diffraction analyzer Bettersizer S3 Plus (Liaoning, China). The studied SAP was a low-crosslinking sodium acrylate that can absorb about $80 \mathrm{~g}$ of distilled water per 1 gram having the powder density of about $600 \mathrm{~kg} / \mathrm{m}^{3}$. Detailed information about the composition of the modified plaster is given in Table 1 . The water/binder ratio was adjusted to obtain the same workability level determined by the flow table test. Particular mixtures were 
denoted as REFP (reference plaster), PLSAP-0.5 - 1.5 (plaster modified by $0.5-1.5$ wt. \% of SAP). The detailed Scanning Electron Microscopy (SEM) image of dried plaster sample with SAP is showed in Figure 1.

Table 1. Composition of the studied plasters.

\begin{tabular}{ccccc}
\hline Mixture & $\begin{array}{c}\text { Dry Plaster } \\
(\mathbf{k g})\end{array}$ & $\begin{array}{c}\text { SAP } \\
(\mathbf{g})\end{array}$ & $\begin{array}{c}\text { Water } \\
\mathbf{( k g})\end{array}$ & $\begin{array}{c}\text { Flow Diameter } \\
(\mathbf{m m})\end{array}$ \\
\hline REFP & 6.3 & - & 1.5 & 180 \\
PLSAP-0.5 & 6.3 & 31.5 & 1.8 & 177 \\
PLSAP-1 & 6.3 & 63 & 2.1 & 181 \\
PLSAP-1.5 & 6.3 & 94.5 & 2.3 & 183 \\
\hline
\end{tabular}

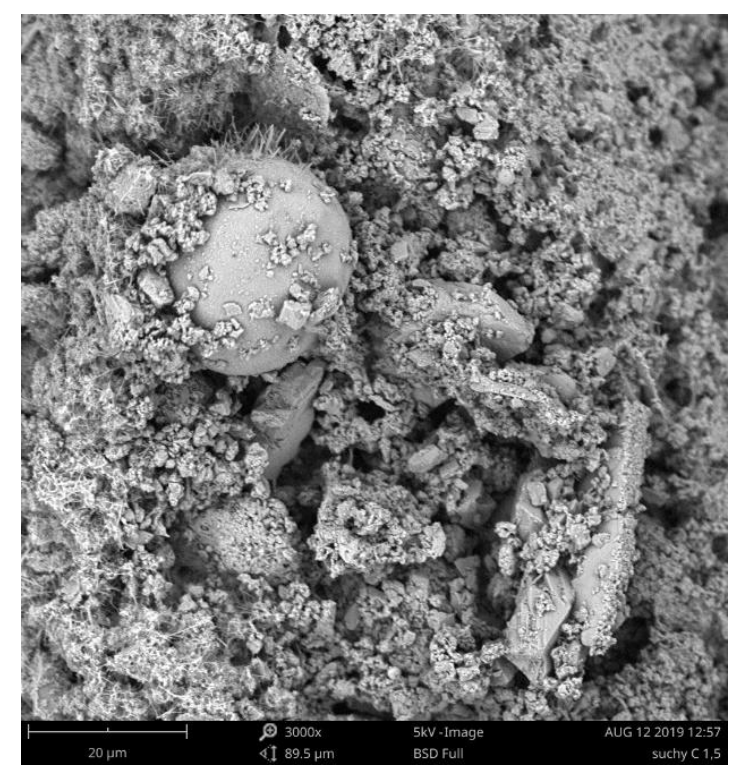

Figure 1. Scanning Electron Microscopy (SEM) image of dried PLSAP-1.5.

Casted samples were stored for 28 days in a humid environment. After the curing period, all samples were dried at $70{ }^{\circ} \mathrm{C}$ for $48 \mathrm{~h}$ until constant mass and subjected to selected experimental procedures.

\subsection{Determination Methods}

The methodology methods selected within this research were used for the description of changes in the material parameters, hygric parameters in particular to access a modification induced by the SAP admixture.

For an understanding of changes in the material structure, the basic physical parameters by the meaning of the total open porosity, bulk and matrix density were determined. First, the bulk density was calculated from the measured volume and dry mass of samples. Matrix density was calculated with the help of the helium pycnometry device Pycnomatic ATC (Thermo Scientific, Waltham, MA, USA). Consequently, the total open porosity was calculated from the values of bulk and matrix density. The effect of applied SAP admixture on material porosity and pore size distribution was studied by mercury intrusion porosimetry (MIP) with the help of Pascal 140 and Pascal 440 porosimeters (Thermo Scientific, Waltham, MA, USA). At the evaluation of measured data, the circular cross-section of capillaries was assumed, whereas the mercury contact angle was $130^{\circ}$ [34].

The water vapor diffusion resistance factor $\mu(-)$ was estimated through the cup determination method carried out at $21^{\circ} \mathrm{C}$. The principle of the measurement consists of 1-D water vapor transmission through a sample; thus the diffusion water vapor flux is driven by a difference between partial pressure 
of water vapor of the air below and above the sample surface. During the experiment, the water vapor flux and partial pressures were tracked. Within the measuring period, the upper and lower relative humidity, i.e., above and below the sample, as defined by $5 \%$ and $50 \%$ of relative humidity, respectively. Afterward, the water vapor diffusion permeability $\delta$ (s) was obtained from measured data according to the following equation

$$
\delta=\frac{\Delta m \cdot d}{S \cdot \tau \cdot \Delta p_{p}}
$$

where $\Delta m(\mathrm{~kg})$ is the amount of water vapor diffused through the sample, $d(\mathrm{~m})$ the sample thickness, $S\left(\mathrm{~m}^{2}\right)$ the specimen surface, $\tau$ (s) the period of time related to the transport of mass of water vapor $\Delta m$ and $\Delta p_{\mathrm{p}}(\mathrm{Pa})$ the difference between partial water vapor pressure in the air under and above specific specimen surface. Consequently, the water vapor diffusion coefficient $D\left(\mathrm{~m}^{2} \cdot \mathrm{s}^{-1}\right)$ and water vapor diffusion resistance factor $\mu(-)$ was estimated accordingly to Equations (2) and (3)

$$
\begin{gathered}
D=\delta \frac{R T}{M} \\
\mu=\frac{D_{a}}{D}
\end{gathered}
$$

where $R\left(\mathrm{~J} \cdot \mathrm{K}^{-1} \cdot \mathrm{mol}^{-1}\right)$ is the universal gas constant, $M\left(\mathrm{~kg} \cdot \mathrm{mol}^{-1}\right)$ the molar mass of water, $T(K)$ the absolute temperature and $D_{\mathrm{a}}\left(\mathrm{m}^{2} \cdot \mathrm{s}^{-1}\right)$ the diffusion coefficient of water vapor in the air.

The sorption and desorption isotherms were determined by the desiccator method at relative humidity levels about $25 \%, 50 \%, 75 \%$ and $98 \%$ of relative humidity (RH). In this experiment, the samples were arranged in desiccators with various salt solutions to achieve different values of relative humidity required to the material description, thus the mass of samples was measured in specified periods until steady-state values of mass were achieved. Subsequently, the moisture content $w\left(\mathrm{~m}^{3} \cdot \mathrm{m}^{-3}\right)$ was calculated and the $w=w(\varphi)$ functions for particular plasters, i.e., the sorption isotherms were plotted [35].

The water sorptivity experiment was employed for the determination of the apparent moisture diffusivity. Here, specimens were firstly water-proof insulated on all lateral sides and immersed $2 \mathrm{~mm}$ under the water level and hanged on automatic balances. The changes in samples mass were continuously monitored, so the water absorption coefficient $A\left(\mathrm{~kg} \cdot \mathrm{m}^{-2} \cdot \mathrm{s}^{-1 / 2}\right)$ was thus calculated as

$$
A=\frac{i}{\sqrt{t}}
$$

where $i\left(\mathrm{~kg} \cdot \mathrm{m}^{-2}\right)$ is the cumulative water absorption and $t(\mathrm{~s})$ the time from the beginning of the mass measurement. The apparent moisture diffusivity $\kappa_{\text {app }}\left(\mathrm{m}^{2} \cdot \mathrm{s}^{-1}\right)$ was calculated using the data revealed from the water absorption coefficient determination and vacuum saturation moisture content, according to the basic formula given in Kumaran [36]

$$
\kappa_{\text {app }}=\left(\frac{A}{w_{\text {sat }}-w_{0}}\right)^{2}
$$

where $w_{\text {sat }}\left(\mathrm{kg} \cdot \mathrm{m}^{-3}\right)$ is the saturated moisture content and $w_{0}\left(\mathrm{~kg} \cdot \mathrm{m}^{-3}\right)$ the initial moisture content.

\subsection{Computational Analysis}

For the investigation of the effect of SAP-modified plasters on the interior relative humidity, a new model was developed. The model calculates an equilibrium relative humidity of the one-dimensional system that consists of the interior plasters and indoor air. The equilibrium is calculated for each hour during the simulation. The system is defined with several parameters, such as plaster thickness, room width and room temperature. The hygric properties of the plaster are defined using sorption isotherm, 
the sorption capability of the air is calculated using saturated water vapor pressure and ideal gas law. The model assumes certain simplifications in order to allow fast calculations. First, it is assumed that no moisture gains or losses are realized through the interior plaster. The only increase or decrease in moisture balance comes from the interior loadings, such as moisture generation by appliances or users or moisture loss through ventilation. The interior loading is defined by time variation of relative humidity that enters the simulation in the form of boundary condition. Second, the entire system is considered as isothermal, which is believed to be sufficient for the demonstration of the effect of SAP plasters on the interior relative humidity. The model provides enough room for extensions such as involving a non-isothermal process by including the sorption isotherms determined at various temperatures, heat and moisture transport through the building envelope, etc. However, in this case, it is assumed that the model in the current simplified form is good enough to reveal the effect of various SAP plasters on the indoor environment.

In the calculations, the saturation pressure of water vapor is calculated from user-defined room temperature according to the updated Tetens equation $[37,38]$ as

$$
p_{v, \text { sat }}= \begin{cases}610.78 \exp \left(\frac{17.269 T}{T+237.3}\right), & \text { for } T \geq 0 \\ 610.78 \exp \left(\frac{21.875 T}{T+265.5}\right), & \text { for } T<0\end{cases}
$$

where $p_{\mathrm{v}, \text { sat }}(\mathrm{Pa})$ is the saturation vapor pressure and $T\left({ }^{\circ} \mathrm{C}\right)$ is the room temperature.

Once the saturation water pressure is known, the initial mass of the water vapor calculated per $1 \mathrm{~m}^{2}$ of the wall can be expressed using the general gas equation as

$$
a_{\mathrm{air}, \text { init }}=\frac{m}{V} \times l=\frac{\varphi_{\text {init }} p_{\mathrm{v}, \mathrm{sat}} M}{R T} \times l
$$

where $a_{\text {air,init }}\left(\mathrm{kg} \cdot \mathrm{m}^{-2}\right)$ is the initial mass of the water vapor calculated per $1 \mathrm{~m}^{2}$ of the wall, $m(\mathrm{~kg})$ is the mass of water vapor in the air, $V\left(\mathrm{~m}^{3}\right)$ is the air volume, $l(\mathrm{~m})$ is the room length, $\varphi_{\text {init }}(-)$ is the initial relative humidity of the air, $M\left(\mathrm{~kg} \cdot \mathrm{mol}^{-1}\right)$ is the molar mass of water and $R\left(\mathrm{~J} \cdot \mathrm{K}^{-1} \cdot \mathrm{mol}^{-1}\right)$ is the universal gas constant.

Similarly, the initial mass of moisture retained in the interior plaster is calculated from the sorption isotherm as

$$
a_{\mathrm{pl}, \text { init }}=w\left(\varphi_{\text {init }}\right) \rho_{w} \times d
$$

where $a_{\mathrm{pl} \text {,init }}\left(\mathrm{kg} \cdot \mathrm{m}^{-2}\right)$ is the initial mass of the water calculated per $1 \mathrm{~m}^{2}$ of the wall, $w\left(\varphi_{\text {init }}\right)\left(\mathrm{m}^{3} \cdot \mathrm{m}^{-3}\right)$ is the volumetric moisture content calculated from sorption isotherm, $\rho_{\mathrm{w}}\left(\mathrm{kg} \cdot \mathrm{m}^{-3}\right)$ is the density of water and $d(\mathrm{~m})$ is the thickness of interior plaster.

The total initial mass of moisture in the system is then calculated as

$$
a_{\text {init }}=a_{\text {air,init }}+a_{\mathrm{pl}, \text { init }}
$$

If the relative humidity of the interior air changes, the new equilibrium is sought while preserving new total mass of the moisture in the system determined as

$$
a_{\text {new }}=a_{\text {init }}+\Delta a_{\mathrm{air}}
$$

with

$$
\Delta a_{\text {air }}=\frac{\varphi_{\text {new }} p_{\mathrm{v}, \text { sat }} M}{R T} \times l-a_{\text {air, init }}
$$

where $\varphi_{\text {new }}(-)$ is the changed relative humidity of the air.

In the next step, the model is searching for the equilibrium relative humidity $\varphi_{\text {eq }}$ that fulfills the following balance equation

$$
a_{\text {new }}=a_{\text {air }}\left(\varphi_{\text {eq }}\right)+a_{\mathrm{pl}}\left(\varphi_{\text {eq }}\right)
$$


where $a_{\text {air }}\left(\varphi_{\text {eq }}\right)$ is the mass of the water in the air per $1 \mathrm{~m}^{2}$ of the wall calculated from Equation (7) and $a_{\mathrm{pl}}\left(\varphi_{\mathrm{eq}}\right)$ is the mass of the water retained in the $1 \mathrm{~m}^{2}$ of the plaster calculated from Equation (8). Since the sorption isotherm is mostly defined by a piecewise linear function, the seeking for the equilibrium relative humidity must be done on the basis of the iteration procedure.

\section{Results and Discussion}

Basic material properties of designed plasters with the SAP admixture are given in Table 2. Here, revealed changes in the material structure clearly document a substantial effect of applied SAPs on material properties. As one can see, an increased amount of SAP content in mixture induced a reduction in the bulk density, while the matrix density was kept almost at the same level. The particular importance needs to be paid on the changes in the amount of pores since the water vapor absorption correlates with the volume of the porous space [39]. The lowest total porosity belonged to the reference plaster, while the modified plaster by SAPs resulted in an increased level of porosity. Namely, the incorporation of SAPs admixtures shifted porosity in $5 \%$ steps to almost $50 \%$ for the PLSAP- 1.5 mixture. Considering the effects of SAP admixture, the most distinct changes were observed in the macroporous range. While the volume of pores of the reference plaster in the macroporous range was minimal, as is typical for cementitious composites, the volume of macropores of novel designed plasters with SAP altered substantially. On the other hand, the changes in the microporous range reached between $10 \%$ and $20 \%$ dependent on the particular mixture. The average pore diameter remained at the same level for all mixtures (approximately $0.025 \mu \mathrm{m}$ ), only the median pore diameter was slightly increased from 0.87 for the reference plaster to $1.34 \mu \mathrm{m}$ for PLSAP-1.5. All noticed changes in the porous space were gradual without any thresholds. Revealed modifications can be assigned to higher consumption of the batch water as a consequence of reduced workability of fresh mixtures. Additionally, adjustments in water content induced a rapid swelling of SAP particles, thus larger void formation in modified plasters. The more detailed analysis aimed at pore size distribution in particular plasters is given in Figure 2.

Table 2. Basic material properties of studied plasters.

\begin{tabular}{cccc}
\hline Mixture & Matrix Density $\mathbf{( k g \cdot \mathbf { m } ^ { - 3 } )}$ & Bulk Density $\mathbf{( k g \cdot \mathbf { m } ^ { - 3 } )}$ & TOP (\%) \\
\hline REFP & 2574 & 1597 & 38.0 \\
PLSAP-0.5 & 2557 & 1482 & 42.0 \\
PLSAP-1 & 2541 & 1420 & 44.1 \\
PLSAP-1.5 & 2550 & 1284 & 49.6 \\
\hline
\end{tabular}

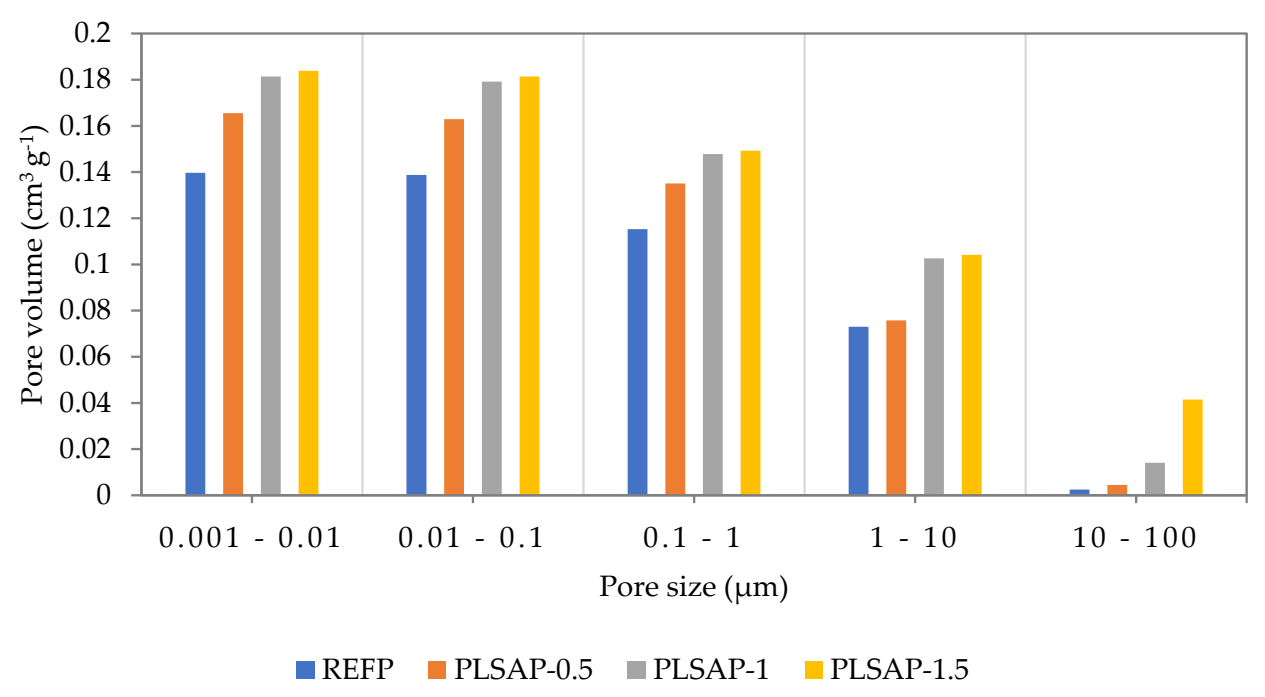

Figure 2. Pore size distribution of studied plasters. 
To reveal modifications in moisture transport properties, the water absorption coefficient and moisture diffusivity were determined. The results shown in Table 3 refer to the substantial effect of applied SAP admixture as well as above-described changes in the material microstructure. Looking at the results, substantial improvement in the water absorption coefficient was noted. Specifically, the water absorption coefficient increased from an initial $0.0798 \mathrm{~kg} \cdot \mathrm{m}^{-2} \mathrm{~s}^{-1 / 2}$ for the reference mixture to $0.2547 \mathrm{~kg} \cdot \mathrm{m}^{-2} \mathrm{~s}^{-1 / 2}$ for the mixture modified by $1.5 \mathrm{wt} . \%$ of SAP. Obtained results correlated with the above-described changes in the material porosity as a result of the formation of the voids during the material preparation due to a rapid swelling capability. However, after the desiccation of specimens, dried SAP particles remained trapped in the voids ready to swell again. This phenomenon is extensively studied and utilized in high-performance concrete mixture design as an effective solution for autogenous shrinkage mitigation [40]. Since the incorporation of SAPs into plasters or mortars was studied only rarely the limited comparison with similar studies is available. In this sense, the work of Senff et al. [32] did not reveal a clear relationship between the amount of used SAP and the water absorption coefficient and rather influence of initial $\mathrm{w} / \mathrm{b}$ ratio was found as a dominant factor. On the other hand, a further swelling of SAPs may create an impermeable layer if SAP particles will be fully saturated [29]. However, the described formation of discontinuous voids was not observed in our work and the water absorption revealed a linear dependency similar to findings revealed by Vieira et al. [41], who, contrary to Senff et al. [32] highlighted the creation of interconnected porous structure thanks to SAP admixture.

Table 3. Moisture transport properties of studied plasters.

\begin{tabular}{|c|c|c|}
\hline Mixture & $A\left(\mathrm{~kg} \cdot \mathrm{m}^{-2} \cdot \mathrm{s}^{-1 / 2}\right)$ & $K\left(\mathrm{~m}^{2} \cdot \mathrm{s}^{-1}\right)$ \\
\hline REFP & 0.0798 & $1.61 \times 10^{-8}$ \\
\hline PLSAP-0.5 & 0.1369 & $2.91 \times 10^{-8}$ \\
\hline PLSAP-1 & 0.1875 & $2.87 \times 10^{-7}$ \\
\hline PLSAP-1.5 & 0.2547 & $5.70 \times 10^{-7}$ \\
\hline
\end{tabular}

The understanding of the water vapor transport properties is deemed crucial for accessing the moisture buffering potential of finishing layers [24]. In this sense, the water vapor resistance factor, water vapor diffusivity, and the water vapor diffusion permeability were calculated from the dry cup method arrangement. Looking at the results (see Table 4, one can see a substantial effect of applied SAP admixture. Namely, while the application of only $0.5 \mathrm{wt} . \%$ decreased the water vapor resistance factor of about $10 \%$, the plaster with $1.5 \mathrm{wt} . \%$ resulted in a $40 \%$ reduction. This fact complies with the observed increased open porosity and high water absorption of SAP particles. On the contrary, exposure to elevated relative humidity levels did not result in the formation of an impermeable layer as noted for liquid water exposure. The elucidation of this difference lays in the gradual saturation of SAP particles and limited swelling. The sorption and desorption isotherms obtained at $21^{\circ} \mathrm{C}$ are plotted in Figure 3 to access the relative humidity sensitivity of designed plasters. As one can see, the absorption rate of modified mixtures differed substantially compared to the reference plaster. In fact, the plaster with $1.5 \mathrm{wt} . \%$ of SAP exhibited the best relative humidity response in the sense of the moisture buffering potential. Namely, the mass increase of the PLSAP-1.5 was 5 times higher. This finding can be assigned to the extensive capability of SAP particles to absorb water molecules. Achieved results provide even more favorable results compared to the work of Vieira et al. [41]. On the other hand, a substantial hysteresis was revealed in line with the increased content of SAP admixture. Considering the experimentally accessed results, plasters modified by SAPs could provide an effective and passive alternative for adjustment of the indoor moisture level and mitigation of potential negative consequences of undesired level of moisture and relative humidity. 
Table 4. Water vapor transport properties of studied plasters.

\begin{tabular}{llll}
\hline \multicolumn{1}{c}{ Mixture } & $\boldsymbol{\mu}(-)$ & $\boldsymbol{D}\left(\mathbf{m}^{\mathbf{2}} \cdot \mathbf{s}^{-\mathbf{1}}\right)$ & $\delta(\mathbf{s})$ \\
\hline REFP & 15.8 & $1.563 \times 10^{-6}$ & $1.15 \times 10^{-11}$ \\
PLSAP-0.5 & 14.3 & $1.727 \times 10^{-6}$ & $1.28 \times 10^{-11}$ \\
PLSAP-1 & 12.3 & $2.008 \times 10^{-6}$ & $1.48 \times 10^{-11}$ \\
PLSAP-1.5 & 9.4 & $2.628 \times 10^{-6}$ & $1.94 \times 10^{-11}$ \\
\hline
\end{tabular}

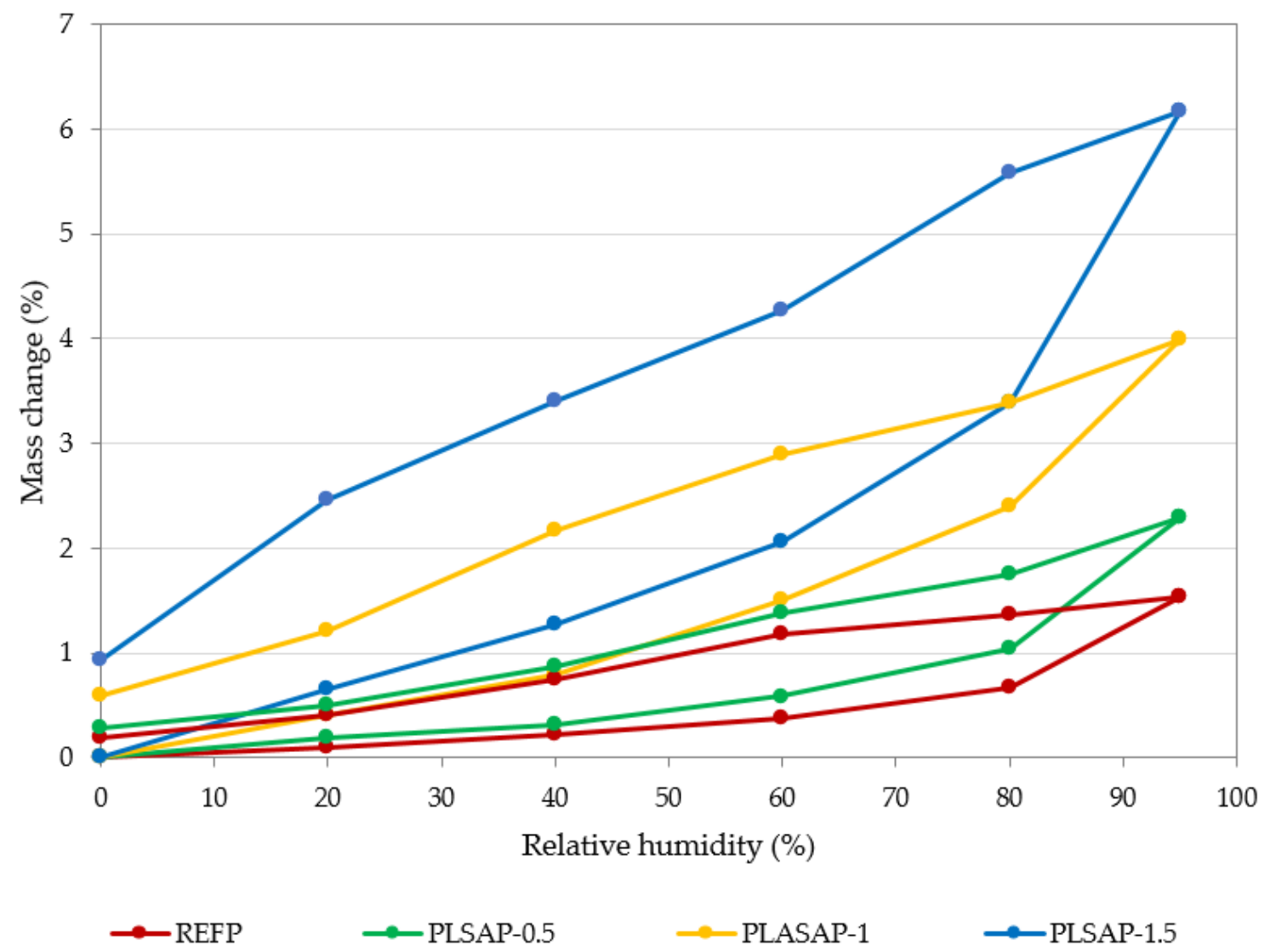

Figure 3. Sorption and desorption isotherms of studied plasters.

Since the quality of the indoor air poses one of the most important tasks for material designers and building engineers, the material parameters of novel plasters with SAP admixture were used as input parameters for computational modeling, which allow effective comparisons of the moisture buffering capability. The promising potential of SAP for moisture buffering was partially described in the work of Goncalves et al. [33], thus SAP utilization should be preferred over lightweight materials such as vermiculite or perlite. The effect of SAP plasters on the indoor relative humidity distribution was investigated in a room with a length of 5 meters that was provided with two plasters having thickness $2 \mathrm{~cm}$. The interior was loaded with relative humidity cycles according to the following scenario: $80 \%$ of relative humidity from 8 a.m. to 8 p.m., $30 \%$ of relative humidity from 9 p.m. to 7 a.m. Initial relative humidity was set to $30 \%$, the temperature during the entire simulation was kept at $21^{\circ} \mathrm{C}$. Based on the experimentally accessed data, the computational modeling allows for simulation of the material response that can be accepted more reliable for building engineers and material designers compared to the standard material testing. The scheme of the simulation is shown in Figure 4. Obtained results for the described conditions revealed a favorable effect of modified plasters on the maintenance of the desired level of the relative humidity. As one can see, the reference plaster does provide only a minimal moisture buffering effect, thus indoor environment suffers by undesired fluctuations and peak relative humidity level in particular. The detailed results are plotted in Figure 5, where the mitigation 
in relative humidity variations is clearly visible. While the reference plaster maintained due to limited buffering capacity fluctuations between $70 \%$ and $36 \% \mathrm{RH}$, the modified plasters refer to more distinct moisture buffering performance. Specifically, the most favorable results achieved for the plaster with $1.5 \mathrm{wt}$ \% of SAP exhibited a reduction of almost $14 \%$ RH compared to the reference plaster a thus kept the relative humidity at the desired level $[17,42]$. This beneficial effect was revealed for all modified plasters according to the amount of SAP used.

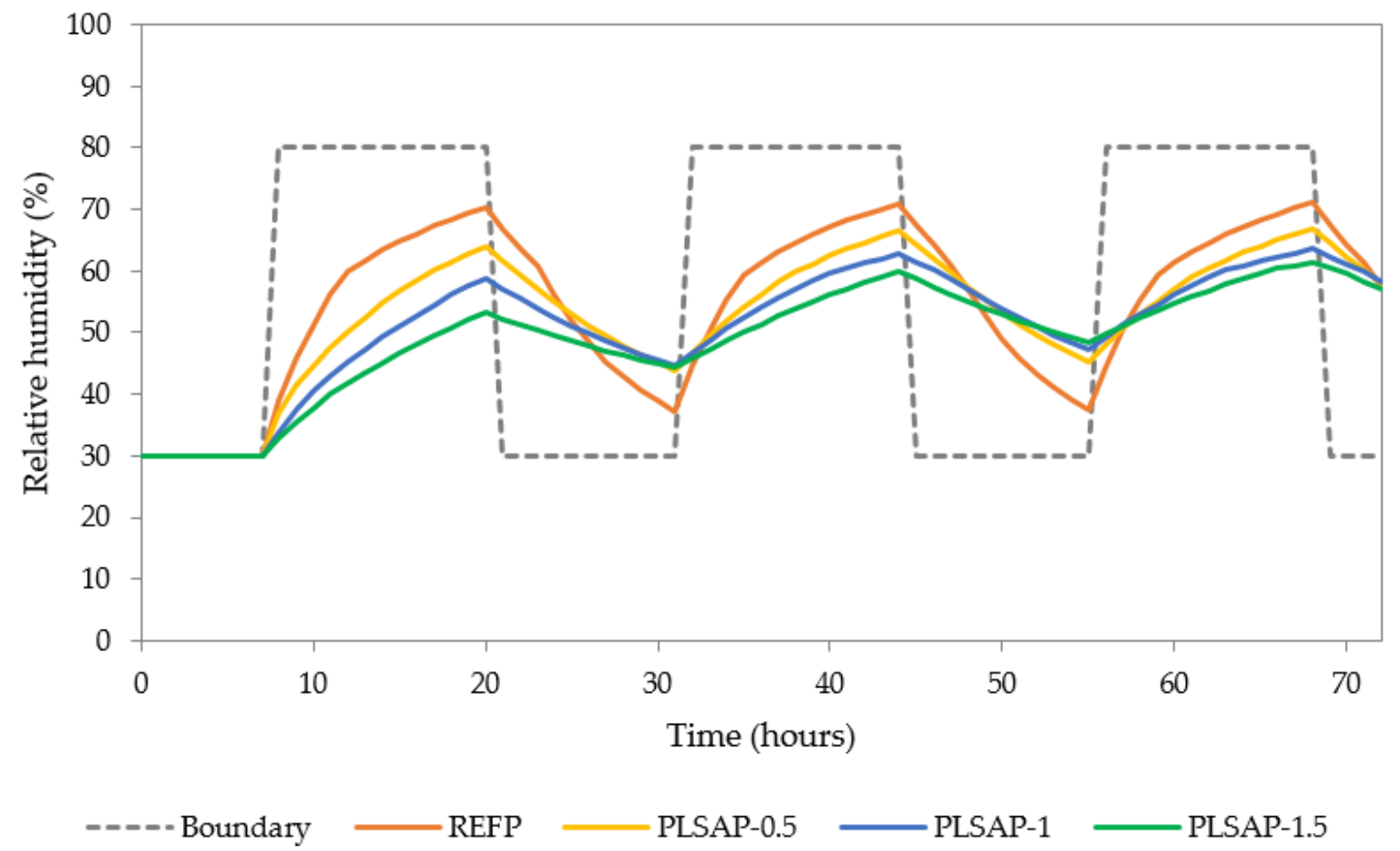

Figure 4. Simulation of relative humidity variations.

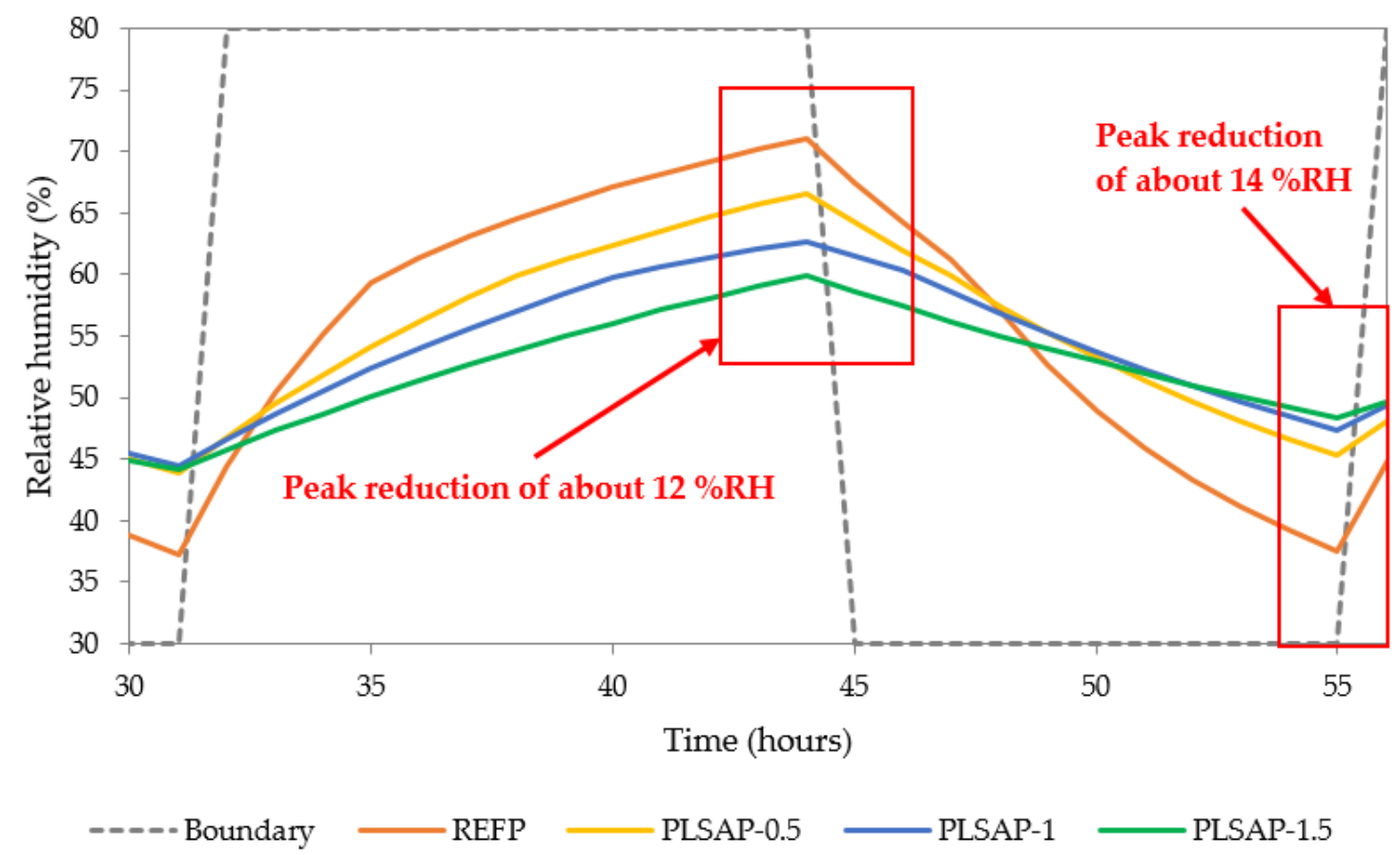

Figure 5. Detail of diurnal relative humidity variations. 
The occupants' thermal comfort or discomfort models often employed for determination of optimal interior conditions take into account also the sensitivity related to skin wetness. Therefore, the improved moisture buffering impact includes an impact on energy consumption since the humidity affects thermal comfort perception [43]. As can be found in the literature, an average person generates between 115 to $270 \mathrm{~g}$ of water per hour. Thus, the indoor moisture loads depend substantially on the occupancy level and associated activities [44].

Taking into account the present issues related to the Building Sick Syndrome and other negative health effects accompanied by the unfavorable quality of the indoor air, the relative humidity in interiors still poses an open challenge especially in the case of highly insulated passive buildings [45]. Consequent mold occurrence in the case of excessive relative humidity or pharyngeal and skin dryness for dry air pose a significant discomfort with adverse effects that impair the life quality. As described in this study, the conventional materials do not provide adequate buffering performance and in several cases even worsening indoor climate [8]. The moisture buffering potential expressed by the moisture buffer value (MBV) commonly determined by the Nordtest protocol [46] varied significantly. On the one hand, the beneficial results achieved by several natural-based materials struggle with higher variability and poses a drawback preventing their wider utilization [23]. The utilization of carnauba wax was found as capable to improve the MBV from 0.3 to $1.1 \mathrm{~g} / \Delta \mathrm{RH} / \mathrm{m}^{2}$, however, on the other hand, the expected improvement may not occur due to the affinity of natural fibers for moisture [24]. The novel materials, such as superabsorbent polymers represent a promising group of materials that may find utilization in traditional building and finishing materials to mitigate negative consequences associated with moisture content. A major effort was paid until now for the application of SAPs for reduction of autogenous shrinkage or self-healing promotion, notwithstanding, several alternatives can be found since SAPs can absorb up to $150,000 \%$ of the water of the dry weight [29]. Moreover, due to rapid swelling, such materials can accelerate the moisture buffering without any major drawbacks. Nonetheless, proper incorporation of SAPs in plasters requires intensive research.

\section{Conclusions}

This study focused on the use of SAPs in cement-lime plasters, extended the current state of knowledge and outlined further possible development of novel moisture responsive plasters. In this paper, the experimental analysis of novel plasters modified by $0.5,1$ and $1.5 \mathrm{wt} \%$ of SAP was carried out to obtain parameters for computational modeling. Archived results indicate that the SAP enhanced plasters had substantial moisture buffering performance and thus might contribute to the mitigation of relative humidity fluctuations. The particular findings should be highlighted as follows:

- The obtained results showed that even small portions of incorporated SAP admixture induced changes in the total open porosity as a result of the worsening of rheologic properties and swelling capability of SAP particles.

- The incorporation of SAP admixture resulted in a substantial increase in moisture transport properties including the water absorption coefficient and water vapor diffusion properties.

- Sorption and desorption isotherms improvement refer to significant moisture buffering potential.

- The performed computational modeling revealed a considerable reduction of relative humidity fluctuations, thus mitigation of potential health issues associated with undesired moisture content in building interiors.

In other words, the utilization of SAP became an attractive topic for the modification of traditional building materials, thus further and detailed investigation is required for the understanding of the material response, and accompanied consequences.

Author Contributions: Conceptualization, J.F., R.Č.; methodology, J.K., J.F., J.P.; validation, J.F., J.K.; formal analysis, R.Č.; investigation, J.F., J.P., J.K.; resources, J.F., J.P., R.Č.; data curation, J.F., J.K.; writing一original draft preparation, J.F., J.K.; writing-review and editing, J.K.; visualization, J.F.; supervision, R.Č.; project administration, J.F.; funding acquisition, J.F., J.P. All authors have read and agreed to the published version of the manuscript. 
Funding: This research was funded by the Czech Science Foundation, under project No. 18-03997S and specific university research of the Institute of Technology and Business in České Budějovice, under project No. ID 8210-009.

Conflicts of Interest: The authors declare no conflict of interest.

\title{
Nomenclature
}

MIP

SAP

SEM

HVAC

$\delta \quad s$

$\mu \quad-$

D $\quad \mathrm{m}^{2} \cdot \mathrm{s}^{-1}$

$\mathrm{m} \quad \mathrm{kg}$

d $m$

$\mathrm{S} \quad \mathrm{m}^{2}$

$\tau \quad \mathrm{S}$

$\mathrm{P}_{\mathrm{p}} \quad \mathrm{Pa}$

$\mathrm{R} \quad \mathrm{J} \cdot \mathrm{K}^{-1} \cdot \mathrm{mol}^{-1}$

$\mathrm{M} \quad \mathrm{kg} \cdot \mathrm{mol}^{-1}$

$\mathrm{T} \quad \mathrm{K}$

$D_{\mathrm{a}} \quad \mathrm{m}^{2} \cdot \mathrm{s}^{-1}$

RH $\%$

w $\quad \mathrm{m}^{3} \cdot \mathrm{m}^{-3}$

A $\quad \mathrm{kg} \cdot \mathrm{m}^{-2} \cdot \mathrm{s}^{-1 / 2}$

i $\quad \mathrm{kg} \cdot \mathrm{m}^{-2}$

Kapp $\quad \mathrm{m}^{2} \cdot \mathrm{s}^{-1}$

$w_{\text {sat }} \quad \mathrm{kg} \cdot \mathrm{m}^{-3}$

$w_{0} \quad \mathrm{~kg} \cdot \mathrm{m}^{-3}$

$p_{\mathrm{v}, \text { sat }} \quad \mathrm{Pa}$

$a_{\text {air,init }} \quad \mathrm{kg} \cdot \mathrm{m}^{-2}$

$\rho \quad \mathrm{kg} \cdot \mathrm{m}^{-3}$

$\varphi_{\text {new }} \quad-$

$a_{\mathrm{pl}} \quad \varphi_{\mathrm{eq}}$

MBV $\quad \mathrm{g} \cdot \mathrm{m}^{-2} . \% \mathrm{RH}^{-1}$

TOP

\author{
Mercury Intrusion porosimetry \\ Superabsorbent polymer \\ Scanning Electron Microscopy \\ Heat, ventilation and air-conditioning \\ water vapor diffusion permeability \\ water vapor diffusion resistance factor \\ water vapor diffusion coefficient \\ mass \\ sample thickness \\ sample surface \\ period of time related to the transport of mass of water vapor \\ partial water vapor pressure \\ universal gas constant \\ molar mass \\ absolute temperature \\ diffusion coefficient of water vapor in the air \\ relative humidity \\ volumetric moisture content \\ water absorption coefficient \\ cumulative water absorption \\ apparent moisture diffusivity \\ saturated moisture content \\ initial moisture content \\ saturation vapor pressure \\ initial mass of the water calculated per $1 \mathrm{~m}^{2}$ of the wall \\ density \\ changed relative humidity of the air \\ mass of the water retained in the $1 \mathrm{~m}^{2}$ of the plaster \\ moisture buffer value \\ total open porosity
}

\section{References}

1. Ricciu, R.; Besalduch, L.A.; Galatioto, A.; Ciulla, G. Thermal characterization of insulating materials. Renew. Sustain. Energy Rev. 2018, 82, 1765-1773. [CrossRef]

2. Shehadi, M. Review of humidity control technologies in buildings. J. Build. Eng. 2018, 19, 539-551. [CrossRef]

3. Nizovtsev, M.I.; Letushko, V.N.; Borodulin, V.Y.; Sterlyagov, A.N. Experimental studies of the thermo and humidity state of a new building facade insulation system based on panels with ventilated channels. Energy Build. 2020, 206, 12. [CrossRef]

4. Lee, H.; Ozaki, A.; Lee, M.; Yamamoto, T. Humidity control effect of vapor-permeable walls employing hygroscopic insulation material. Indoor Air 2020, 30, 346-360. [CrossRef]

5. Yu, S.; Cui, Y.M.; Shao, Y.F.; Han, F.H. Research on the Comprehensive Performance of Hygroscopic Materials in an Office Building Based on EnergyPlus. Energies 2019, 12, 191. [CrossRef]

6. Maděra, J.; Jerman, M.; Čáchová, M.; Doleželová, M.; Kočí, J. Computational Modelling of Degradation Processes in Exterior Renders. In Proceedings of the International Conference of Numerical Analysis and Applied Mathematics, Rhodes, Greece, 13-18 September 2018.

7. Yu, M.; Zhang, X.J.; Zhao, Y.; Zhang, X.B. A Novel Passive Method for Regulating Both Air Temperature and Relative Humidity of the Microenvironment in Museum Display Cases. Energies 2019, 12, 3768. [CrossRef] 
8. Kreiger, B.K.; Srubar, W.V. Moisture buffering in buildings: A review of experimental and numerical methods. Energy Build. 2019, 202, 17. [CrossRef]

9. Nguyen, C.K.; Teodosiu, C.; Kuznik, F.; David, D.; Teodosiu, R.; Rusaouen, G. A full-scale experimental study concerning the moisture condensation on building glazing surface. Build. Environ. 2019, 156, $215-224$. [CrossRef]

10. Govaerts, Y.; Hayen, R.; de Bouw, M.; Verdonck, A.; Meulebroeck, W.; Mertens, S.; Gregoire, Y. Performance of a lime-based insulating render for heritage buildings. Constr. Build. Mater. 2018, 159, 376-389. [CrossRef]

11. Mazhoud, B.; Collet, F.; Pretot, S.; Chamoin, J. Hygric and thermal properties of hemp-lime plasters. Build. Environ. 2016, 96, 206-216. [CrossRef]

12. Xu, C.C.; Li, S.H.; Zou, K.K. Study of heat and moisture transfer in internal and external wall insulation configurations. J. Build. Eng. 2019, 24, 14. [CrossRef]

13. Pavlik, Z.; Jerman, M.; Fort, J.; Cerny, R. Monitoring Thermal Performance of Hollow Bricks with Different Cavity Fillers in Difference Climate Conditions. Int. J. Thermophys. 2015, 36, 557-568. [CrossRef]

14. Mendell, M.J.; Macher, J.M.; Kumagai, K. Measured moisture in buildings and adverse health effects: A review. Indoor Air 2018, 28, 488-499. [CrossRef] [PubMed]

15. Nakayama, Y.; Nakaoka, H.; Suzuki, N.; Tsumura, K.; Hanazato, M.; Todaka, E.; Mori, C. Prevalence and risk factors of pre-sick building syndrome: Characteristics of indoor environmental and individual factors. Environ. Health Prev. Med. 2019, 24, 10. [CrossRef]

16. Hegarty, B.; Haverinen-Shaughnessy, U.; Shaughnessy, R.J.; Peccia, J. Spatial Gradients of Fungal Abundance and Ecology throughout a Damp Building. Environ. Sci. Technol. Lett. 2019, 6, 329-333. [CrossRef]

17. Nezis, I.; Biskos, G.; Eleftheriadis, K.; Kalantzi, O.I. Particulate matter and health effects in offices-A review. Build. Environ. 2019, 156, 62-73. [CrossRef]

18. Esty, B.; Permaul, P.; DeLoreto, K.; Baxi, S.N.; Phipatanakul, W. Asthma and Allergies in the School Environment. Clin. Rev. Allergy Immunol. 2019, 57, 415-426. [CrossRef]

19. Wan, H.; Sun, Z.W.; Huang, G.S.; Xu, X.H.; Yu, J.H. Calculation of the maximum moisture buffering thickness of building wall layer of hygroscopic material. Build. Environ. 2019, 160, 11. [CrossRef]

20. Busser, T.; Pailha, M.; Piot, A.; Woloszyn, M. Simultaneous hygrothermal performance assessment of an air volume and surrounding highly hygroscopic walls. Build. Environ. 2019, 148, 677-688. [CrossRef]

21. Arrigoni, A.; Beckett, C.T.S.; Ciancio, D.; Pelosato, R.; Dotelli, G.; Grillet, A.C. Rammed Earth incorporating Recycled Concrete Aggregate: A sustainable, resistant and breathable construction solution. Resour. Conserv. Recycl. 2018, 137, 11-20. [CrossRef]

22. De Rossi, A.; Carvalheiras, J.; Novais, R.M.; Ribeiro, M.J.; Labrincha, J.A.; Hotza, D.; Moreira, R. Waste-based geopolymeric mortars with very high moisture buffering capacity. Constr. Build. Mater. 2018, 191, $39-46$. [CrossRef]

23. Nguyen, D.M.; Grillet, A.C.; Diep, T.M.H.; Thuc, C.N.H.; Woloszyn, M. Hygrothermal properties of bio-insulation building materials based on bamboo fibers and bio-glues. Constr. Build. Mater. 2017, 155, 852-866. [CrossRef]

24. Cerolini, S.; D'Orazio, M.; Di Perna, C.; Stazi, A. Moisture buffering capacity of highly absorbing materials. Energy Build. 2009, 41, 164-168. [CrossRef]

25. Zhang, H.B.; Yoshino, H.; Iwamae, A.; Hasegawa, K. Investigating simultaneous transport of heat and moisture in hygroscopic materials by a semi-conjugate CFD-coupled approach. Build. Environ. 2015, 90, 125-135. [CrossRef]

26. Palumbo, M.; Lacasta, A.M.; Holcroft, N.; Shea, A.; Walker, P. Determination of hygrothermal parameters of experimental and commercial bio-based insulation materials. Constr. Build. Mater. 2016, 124, 269-275. [CrossRef]

27. Koci, J.; Koci, V.; Cerny, R. A Method for Rapid Evaluation of Thermal Performance of Wall Assemblies Based on Geographical Location. Energies 2019, 12, 1353. [CrossRef]

28. Senff, L.; Ascensao, G.; Hotza, D.; Ferreira, V.M.; Labrincha, J.A. Assessment of the single and combined effect of superabsorbent particles and porogenic agents in nanotitania-containing mortars. Energy Build. 2016, 127, 980-990. [CrossRef]

29. Zohuriaan-Mehr, M.J.; Kabiri, K. Superabsorbent polymer materials: A review. Iran. Polym. J. 2008, 17, 451-477. 
30. Liu, J.H.; Farzadnia, N.; Shi, C.J.; Ma, X.W. Effects of superabsorbent polymer on shrinkage properties of ultra-high strength concrete under drying condition. Constr. Build. Mater. 2019, 215, 799-811. [CrossRef]

31. Ma, X.W.; Yuan, Q.; Liu, J.H.; Shi, C.J. Effect of water absorption of SAP on the rheological properties of cement-based materials with ultra-low w/b ratio. Constr. Build. Mater. 2019, 195, 66-74. [CrossRef]

32. Senff, L.; Modolo, R.C.E.; Ascensao, G.; Hotza, D.; Ferreira, V.M.; Labrincha, J.A. Development of mortars containing superabsorbent polymer. Constr. Build. Mater. 2015, 95, 575-584. [CrossRef]

33. Goncalves, H.; Goncalves, B.; Silva, L.; Vieira, N.; Raupp-Pereira, F.; Senff, L.; Labrincha, J.A. The influence of porogene additives on the properties of mortars used to control the ambient moisture. Energy Build. 2014, 74, 61-68. [CrossRef]

34. Fort, J.; Novotny, R.; Trnik, A.; Cerny, R. Preparation and Characterization of Novel Plaster with Improved Thermal Energy Storage Performance. Energies 2019, 12, 3318. [CrossRef]

35. Pavlik, Z.; Fiala, L.; Jerman, M.; Vejmelkova, E.; Pavlikova, M.; Keppert, M.; Cerny, R. Theoretical and Experimental Analysis of Moisture-Dependent Thermal Conductivity of Lightweight Ceramic Bricks. Int. J. Thermophys. 2014, 35, 1912-1921. [CrossRef]

36. Kumaran, M.K.; Lackey, J.C.; Normandin, N.; Tariku, F.; van Reenen, D. Heat, air, and moisture transport properties of several North American bricks and mortar mixes. J. Test. Eval. 2004, 32, 383-389. [CrossRef]

37. Monteith, J.L.; Unsworth, M.H. Principles of Environmental Physics, 3rd ed.; Academic Press: Amsterdam, The Netherlads, 2008.

38. Murray, F.W. On the computation of saturation vapour pressure. J. Appl. Meteorol. 1967, 6, $203-204$. [CrossRef]

39. Maia, J.; Ramos, N.M.M.; Veiga, R. Evaluation of the hygrothermal properties of thermal rendering systems. Build. Environ. 2018, 144, 437-449. [CrossRef]

40. Liu, J.M.; Ou, Z.W.; Mo, J.C.; Wang, Y.H.; Wu, H. The effect of SCMs and SAP on the autogenous shrinkage and hydration process of RPC. Constr. Build. Mater. 2017, 155, 239-249. [CrossRef]

41. Vieira, J.; Senff, L.; Goncalves, H.; Silva, L.; Ferreira, V.M.; Labrincha, J.A. Functionalization of mortars for controlling the indoor ambient of buildings. Energy Build. 2014, 70, 224-236. [CrossRef]

42. Johansson, P.; Bok, G.; Ekstrand-Tobin, A. The effect of cyclic moisture and temperature on mould growth on wood compared to steady state conditions. Build. Environ. 2013, 65, 178-184. [CrossRef]

43. Winkler, J.; Munk, J.; Woods, J. Sensitivity of occupant comfort models to humidity and their effect on cooling energy use. Build. Environ. 2019, 162, 14. [CrossRef]

44. Lu, X.S. Estimation of indoor moisture generation rate from measurement in buildings. Build. Environ. 2003, 38, 665-675. [CrossRef]

45. Mlakar, J.; Strancar, J. Temperature and humidity profiles in passive-house building blocks. Build. Environ. 2013, 60, 185-193. [CrossRef]

46. McGregor, F.; Heath, A.; Shea, A.; Lawrence, M. The moisture buffering capacity of unfired clay masonry. Build. Environ. 2014, 82, 599-607. [CrossRef]

(C) 2020 by the authors. Licensee MDPI, Basel, Switzerland. This article is an open access article distributed under the terms and conditions of the Creative Commons Attribution (CC BY) license (http://creativecommons.org/licenses/by/4.0/). 